\title{
Web-based Collaborative Engineering Support System: Applications in Mechanical Design and Structural Analysis
}

\author{
Benoît Eynard, ${ }^{1, *}$ Sébastien Liénard, ${ }^{2}$ Sébastien Charles $^{1}$ and Aurélien Odinot ${ }^{1,2,3}$ \\ ${ }^{1}$ Laboratory of Mechanical Systems and Concurrent Engineering, Troyes University of Technology \\ 12 rue Marie Curie, BP 2060, F.10010 Troyes Cedex, France \\ ${ }^{2}$ Ideamech, 2 avenue de l'Europe, Parc technologique du canal, F.31520 Ramonville Saint Agne, France \\ ${ }^{3}$ Laboratoire d'Ingénierie des Processus et des Services Industriels, \\ Ecole Supérieure des Technologies Industrielles Avancées, Technopole Izarbel, F.64210 Bidart, France
}

\begin{abstract}
The diversity in software used to support collaborative design and concurrent engineering requires the implementation of new technologies in order to ensure the integration between the various activities of the product development process. Most of the time, companies can not afford to spend the time and the funds required to enhance their IT and software resources. This is often the case of small and medium companies. Nowadays, in mechanical design, the needs for product data sharing between Computer Aided Design (CAD) and finite element analysis (FEA) activities have been fairly increased even for small companies. This article aims at presenting Teamproject software, an asynchronous Web Computer Supported Cooperative Work (CSCW) oriented toward the sharing and viewing of 3D data (CAD and FEA) based on Virtual Reality Modeling Language (VRML). Regarding the collaborative design and concurrent engineering approaches, this software increases the information access and its availability to expert and non-expert users in a remote mode.

The article deals with the benefits proposed by the use of Web technologies in mechanical design and structural analysis fields. It details the software architecture of Teamproject. One of the added values offered by the new version of the Web CSCW is the translation of CAD and FEA data into VRML format. It extends the 3D product data review to all the team members involved in a project. Indeed, the reading of the Java3D can be ensured by the most used web navigator (like Internet Explorer and Netscape) with the aid of a free plug-in. To summarize, the proposed Web CSCW provides a simple and efficient access to mechanical design and structural analysis data in a real collaborative engineering approach.
\end{abstract}

Key Words: collaborative design, CSCW, Web, FEA, CAD.

\section{Introduction}

The increase in information sharing, led by multisite distribution of activities and by extended enterprise approaches implemented in many companies, emphasize the requirements of means and tools supporting collaborative work in a remote organization [1,2]. Concurrent engineering and collaborative design methods and tools contribute widely to simplify the development of remote and distributed works [3,4]. Concurrency and distribution of tasks become synonymous with success because of the increasing needs for reactivity and competitiveness for companies. Web technologies represent one of the most powerful tools of exchange, pooling, and distribution of information between project's team members $[5,6]$.

*Author to whom correspondence should be addressed.

E-mail: benoit.eynard@utt.fr
The aim of the article is to present an asynchronous Web Computer Supported Cooperative Work (CSCW) that would enhance the sharing of Computer Aided Design (CAD) and finite element analysis (FEA) data. In the following section, the interest of using Web technologies more widely in mechanical engineering projects is shown. This section also presents a survey of the available technologies and their possible applications in the above-mentioned field. Then, the asynchronous collaborative engineering support system and its main features developed by Ideamech Company are detailed. Finally, the integration of a Java3D viewer is assessed and discussed, and the interests of the presented research work are summarized.

\section{Survey of Web CSCW in Mechanical Design and FE Analysis}

Web-based product data exchanges have a strong development because of the interest shown by 
manufacturers, co-contractors, partners, and suppliers who find there the ideal support of concurrent engineering, extended enterprise, and collaborative design [7,8]. Concurrent engineering introduced the need of tasks distribution and concurrency of activities between several project team members. Extended enterprise required remote work between project teams split up on worldwide units. Lastly, collaborative engineering reinforced the use of information and communication technologies (ICTs) in order to support communication, coordination, and cooperation between project teams in charge of product development.

The large range of software and computer systems and of, intrinsically, legacy file formats raises important difficulties in data exchange, reading, translation, and viewing, especially in a remote mode. To try to solve these matters especially in a web-oriented approach, numerous technologies or standards format come to maturity, such as PHP and XML [9] for dynamic processing of web data, VRML [10] or Java3D [11] for $3 \mathrm{D}$ viewing within web applications, and STEP [12] for product information exchanges.

\subsection{Evolution of Mechanical Design Activities}

Based on the concepts issued from concurrent engineering, extended enterprise and $\mathrm{CSCW}$ approaches, the mechanical engineering activities, which were originally co-localized and mainly sequential, turn henceforth to distribution and concurrent planning of activities in order to reduce costs and lead times as well as to enhance reactivity ability. This evolution of working modes and organizations become one of the main strengths of business and corporate integration. This integration is now mainly based on ICTs allowing taking advantage, remotely and at a lower cost, of skills and know-how while they are physically far away. Regarding collaborative engineering, simultaneous carrying out of tasks by geographically distant project teams is henceforth enabling. This leads to the needs in improving the project management (tasks concurrency) and enabling the co-working of geographically distributed teams. But it means numerous exchanges of information, which come along with further difficulties. Then, the teams also require the setting up of an efficient management and sharing of information, and also remote viewing of data.

The question of physical support to be chosen for data exchange security and for file format remains important. Regarding the method of data transferring, Internet stands out because of its universality in communication and exchange. For example, numerous systems of product lifecycle management (PLM) or collaborative engineering are either entirely Web-based, or they provide a thin Web client $[13,14]$.

\subsection{Web Technologies Integration within Mechanical Design and Structural Analysis Fields}

By historical practice and organizational inheritance, mechanical companies often split up engineering design and structural analysis activities [15]. But in collaborative engineering, these activities should be integrated and merged [16]. The departments involved in a project frequently have to exchange their own works in order to share or to comment on their respective issues. Furthermore, subcontracting development activities toward engineering consultancy companies create strong needs for information sharing between the original equipment manufacturer and its suppliers. On the contrary, to gain reactivity and quality in their performances, those late try to get customer validation as soon as possible on a 3D CAD file, on a preprocessing FEA model or on a preliminary analysis result.

Computer Aided Design models are used as analysis input; then the post-processing results, sometimes, lead to the change of the original CAD model. Information transfer is thus bidirectional and is generally made via a LAN or by Internet. Exchanged data between both fields often require adequate processing, standards, and software allowing the files translation. Regarding a simple viewing approach, it would be interesting to get these data available simply for the right users.

These needs based on the experience of Ideamech Company have led to the development of the Web CSCW presented in Section 3. The lowness of Internet data transfer rate and the size of $3 \mathrm{D} C A D$, preprocessing and post-processing files (often exceeding a dozen $\mathrm{Mb}$ and might exceed several hundreds of $\mathrm{Mb}$ ) led to the use of neutral exchange formats which, although they damage the quality of product data, allow reduction of data volumes. To make, it is necessary to reduce the models size so as to keep the main and relevant part of data. VRML and associated format might help fulfil the visualization needs of CAD and FEA fields regarding current neutral format and to answer Internet data transfer limits. These assumptions led Ideamech to develop Teamproject ${ }^{1}$ : an asynchronous Web CSCW supporting collaborative engineering and mechanical design. In order to enable FEA data viewing via the Internet, a preliminary NASTRAN/ VRML translator had been implemented. Then, for improving the performances of display and handling of 3D data, Sections 4-6 discuss the specification and implementation of a new viewing module based on technologies in compliance with web constraints and collaborative engineering needs.

${ }^{1}$ http://www.ideamech.com 


\section{Teamproject}

Nowadays, products lead times are a key factor of competitiveness. In product development cycle, many companies practice iterative exchanges: a $3 \mathrm{D}$ CAD model is issued and updated during the whole project lifecycle; decisions are made during technical meetings and project reviews until the manufacturing launch. In collaborative engineering, these iterative exchanges have to be minimized and project times reduced. Generally, various project team members have to check the design changes (project manager, designers, mechanical engineers, etc.). In such a context, many data exchanges and information sharing are required $[16,17]$. Three main needs are generally mentioned: communication, coordination, and cooperation. Teamproject has been defined as an asynchronous Web CSCW which allows:

- management and sharing of information (communication),

- management of projects and distributed teams members (coordination),

- remote viewing of CAD and FEA models (cooperation).

Teamproject provides a friendly graphical user interface with a project management workspace (teams, schedule, shared documents, milestones, and tasks) and 3D visualization module for CAD and FEA models.

\subsection{Architecture}

Teamproject is developed based on a three-tier clientserver architecture [7] and on OpenSources technologies: APACHE server, PHP script interpreter, and MySQL database (Figure 1). Teamproject consists of a set of PHP scripts, which allows structuring and storing information in the database.
The software is only implemented on one server connected to the Internet or through the company Intranet, on which all the user workspaces are centralized via the database. Currently, users access the system by simply opening a Web browser. They visualize the features of 3D CAD and FEA models with a VRML plug-in $[17,18]$. This kind of architecture is especially relevant for CAD and FEA activities regarding collaborative engineering context $[19,20]$.

\subsection{Main Functionalities}

Regarding the basic needs for communication, coordination, and cooperation, Teamproject provides several functionalities. This software has been developed around a central core on which modules are attached. The core module provides the graphical user interface features for information display and the features for management of various users' access rights (administrator, co-worker, project manager, etc.).

\subsubsection{MESSAGES AND SHARED FILES}

As regards communication needs, each team member can create, publish, and erase messages as for 'post-it'. These messages are shown on the graphical user interface via a selection of addressees to whom they are sent.

The shared file module allows the exchange of files while they are under working version. This module can be compared to an interfaced FTP application or simply to a remote disk space.

\subsubsection{PROJECTS AND DOCUMENTS MANAGEMENT}

In a virtual organization made up of numerous team members involved in many projects, data management can be difficult [21]. Teamproject allows team members to have a very easy sharing of the required information. Projects and documents management provide useful functionalities for coordination between team members.

Figure 1. Three-tier architecture of Teamproject.

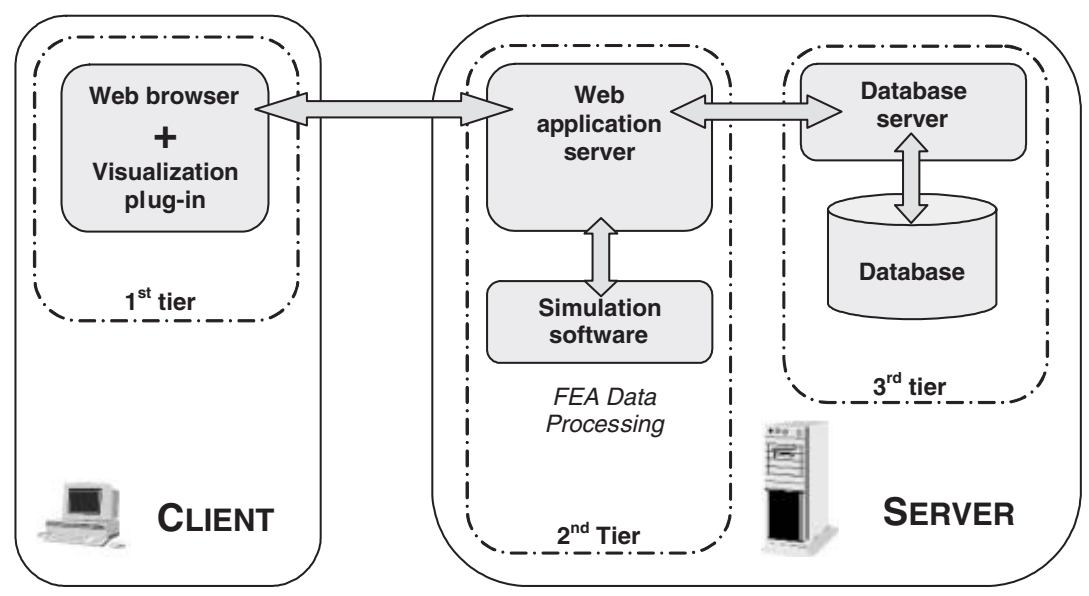


Knowing the project schedule and tasks distribution, they can download necessary documents for their assigned activities.

\section{Milestones and Tasks}

Project managers can check and supervise the schedule and project progress thanks to a two-level organization: milestones and tasks (Figure 2). They specify the milestones and tasks, which may be assigned concurrently to the team members. Milestones and tasks clarify the start and end dates, a brief description of their contents, and mainly the required deliverables.

During the project progress, team members receive updated information via their worklist status regarding the general project progress. Project managers can supervise the project progress, with the summary of the completed, late, and current tasks. When a task is closed, a file can be attached as deliverable and uploaded in the common workspace, and later referenced and shared.

\section{Documents Base}

Documents download/upload within the base can be carried out in two ways: (1) by closing a task for which a deliverable is required, or (2) by creating a new document index card. Several attributes are necessary for document download/upload in the base: project name, author, revision, document type, file, and description. The document management functionality allows each team member to have concurrent data access and then carry their tasks simultaneously. When a document is used, its access for other team members is then read only; no overwriting is possible. Synchronous access is possible but document changes can only be asynchronous.

\subsubsection{CAD AND FEA DATA VISUALIZATION}

Lastly, concerning cooperation needs (currently with a free downloadable VRML 3D plug-in), users can visualize 3D CAD and FEA models within the support of Teamproject for checking design changes and carrying out asynchronous project review. Based on the preliminary experiment of the VRML viewer use, the change of viewing technology and the integration of a new viewer based on Java3D has been decided and will be discussed in Sections 4-6.

\section{CAD Model}

Browsing in CAD model is ensured by a hierarchical organization of the models, which allows selection of the parts for which visualization is needed. Then models can be dynamically handled in 3D with useful features, such as rotation, zoom, pan, and refit. Furthermore, information associated with CAD models, such as part names, comments, author name, and native version is also available via Teamproject.

\section{FEA Model}

Teamproject integrates viewing functionalities of FEA models in order to allow team members to read all information linked to structural analysis without having to implement FEA post-processor. Figure 3 shows the mode shape of a spacecraft sunshield displayed within the Teamproject environment.

Considering the need for remote review of structural analysis issues, all pre-processing information is available in the FEA viewing workspace: meshing, strains, and boundary conditions applied to the model, material, and properties. Then, translation from preprocessor to VRML mainly contains meshing, strains, and boundary conditions for a realistic viewing of pre-processing files. In this preliminary version of the viewer, the translator was implemented with PHP and the data conversion was batch processed and stored in the database.

Post-processing functionalities allow reading and assessing the structural analysis issues. Team members can display and handle deformed views with many shifting and constraint distributions. Vibratory modes can also be used when this kind of analysis has been carried out on a FEA model. Further information, such as maximum and minimum (stresses, shifting), and general information about the analyzed model (size,

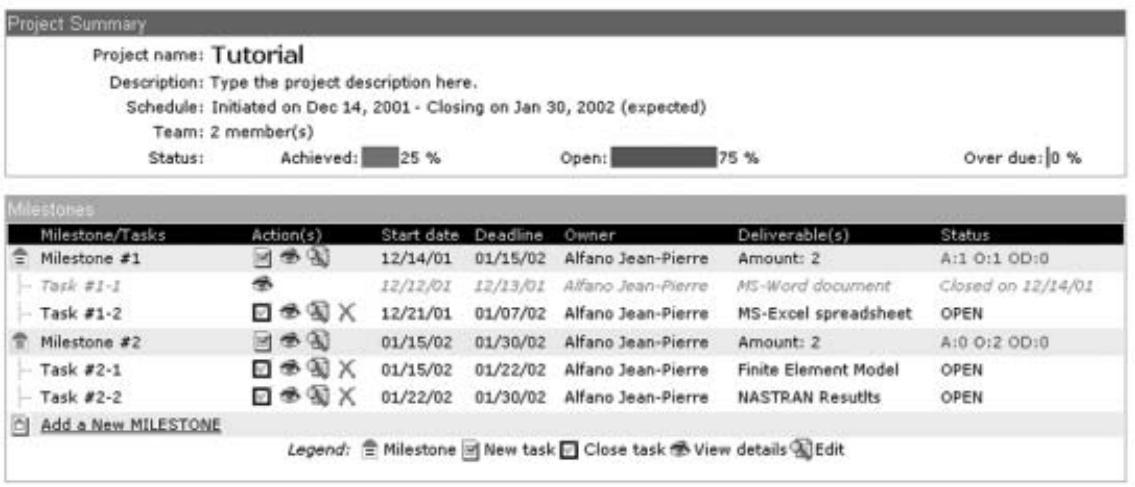

Figure 2. Project status. 


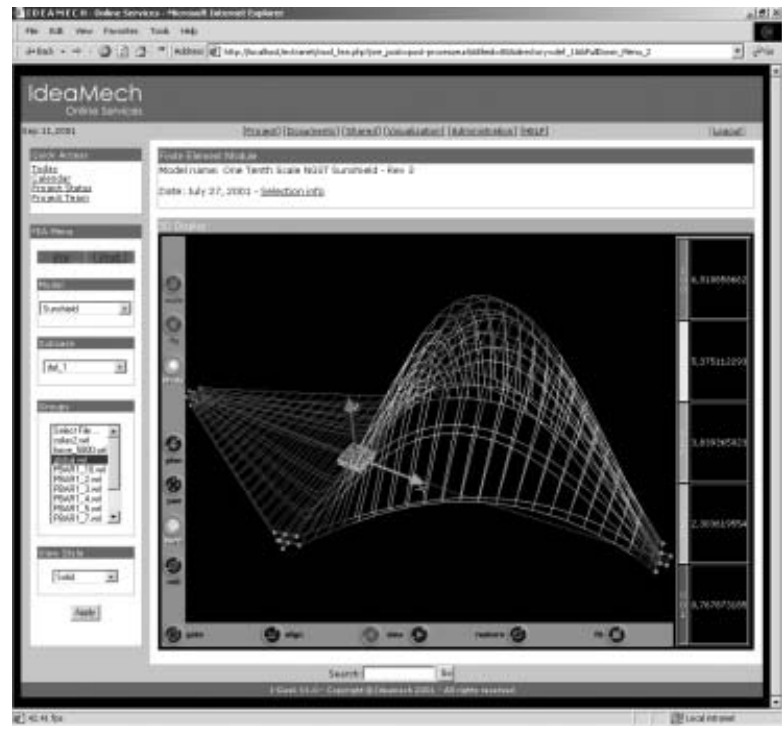

Figure 3. FEA model results display.

mass distribution with localization of center of gravity or inertia, natural frequencies, etc.) are also available.

\section{Requirements for New Finite Element Analysis and Viewer Modules}

Regarding the needs of high interactivity with users, the FEA and viewer modules of Teamproject have to be improved in order to allow an effective dynamic display of data. The nature of web-based modules aims at the development of a distributed architecture enabling an improved tool for analysis processing and remote $3 \mathrm{D}$ displaying of its issues. The original Teamproject specifications have to be kept. Then, these modules have to be web oriented. The analysis module has to run on a server, where an FEA solver is implemented. The visualization of the analysis issues has to be ensured via a web browser client; then the users are not required to be FEA experts in order to validate results. For that job, they will only need basic mechanical engineering know-how.

\subsection{Requirements for the Graphic User Interface}

As regards the needs of distribution for carrying out projects and specificities of Teamproject, the following requirements have been clarified:

- network communication between the server and the client has to be reliable. Regarding Internet/Intranet environment, the classical TCP/IP protocol shall be used,

- currently, the Internet/Intranet bandwidth is relatively low in comparison to the bus bandwidth of a computer, so it is necessary to minimize the number of client-server exchanges,
- the data processing and FEA shall be ensured by the server,

- the web pages interface has to be dynamic regarding the nature of the application,

- the interface shall be able to manage several users simultaneously,

- the installation on the client side shall be limited to a simple plug-in compliance with all standard browsers.

\subsection{Technology Survey for Developing a Dynamic User Interface}

Creating dynamic Web pages interacting with the customized information display is the kernel of $\mathrm{Web}$ application, based on three-tier architecture. For the development of Web applications, several script languages are frequently used. For example, Common Gateway Interface (CGI), Active Server Page (ASP), Person Home Page (PHP), Java Server Pages (JSP), Applet, Servlet, and JavaScript [14,22,23].

Regarding the application needs, the use of a Serverside scripting language to reduce the client side charge has been chosen. As the Applets and JavaScript scripts processing part are implemented on the client side they do not meet the specifications of the above-mentioned needs. Sun Microsystems developed the Java Server Pages (JSP) technology based entirely upon Java programming language. JSP is a better solution to generate dynamic Web pages in comparison to ASP (not compatible with all platforms), PHP (poor database access functions, undeveloped library mechanism), CGI (not multithread), JavaScript scripts, and Applets. Together, the JSP and Servlets technologies seem the most attractive alternative to develop dynamic Web scripting/programming. Indeed, these solutions provide platform independence, enhanced performances, splitting up of logic from display, and easier administration and use. Hence, all these elements validate the choice of the JSP and Servlets to develop a dynamic user interface. Figure 1 describes classical three-tier architecture with the possible technology implementations.

\section{Assessment of 3D Data Visualization Technology}

The next step is to identify the most suitable technology for implementing the visualization module. This module must be able to create a virtual world to support a high interaction level with the user regarding collaborative engineering needs. Considering a 3D FEA model, the minimum interactivity is to be able to view this model from various perspectives. One of the main objectives is to use a viewer which does not need huge hardware requirements and can run on a common 
personal computer (desktop or laptop). Last, the software must be portable and platform independent. The preliminary version of the Teamproject visualization module was based on VRML (see Section 3.2.3), but the interactivity with users was fairly satisfying. Then a survey was necessary to assess available technologies for improving the viewer.

\subsection{Technology Survey for 3D Viewing}

\subsubsection{VRML}

Virtual Reality Modeling Language is a file format for describing interactive 3D objects and worlds. VRML is designed to be used on the Internet, intranet, and local client systems [18]. VRML is also intended to be a universal exchange format for integrated 3D graphics and multimedia. The richness of VRML is due to its interaction and navigation capabilities and also the fact that VRML objects can be hyperlinked to multimedia (image, text, video, audio) or HTML files, as well as to other VRML objects. But it was not widely accepted and used as HTML because of the limitations and the rigidity of the standard. These limitations naturally led to the development of new Web3D formats including Java3D, X3D, and legacy format, which are less rigid and thus more expandable [24].

\subsection{2 $\times 3 D$}

The eXtensible 3D alias X3D aims to be the successor of the VRML. It is developed to solve the VRML problems while taking up the VRML functionalities and integrating new features and new possibilities for data visualization and data exchange (www.web3d.org). X3D is a significant step in the VRML evolution, defined to ensure the best functionalities of VRML and to be fully integrated with XML. In fact, XML seems to be the future file exchange standard for all applications over the Web.

Currently, X3D lack programming language possibilities. Although it provides some means for data description, $\mathrm{X} 3 \mathrm{D}$ is limited regarding data modification. These limitations come from the need to display the scene within the viewing plug-ins. Moreover, due to its lack of maturity, the choice of X3D is not relevant.

\subsubsection{JAVA3D}

The Java3D Application Programming Interface (API) is an interface for writing programs with 3D display and 3D models interaction. It offers many properties, such as being simple, portable, secure, robust, multithreaded, distributed, and object-oriented. In addition to the inherent strengths of the Java language, Java3D extends the concept of 'Write Once, Run Anywhere' to the development of 3D graphics applications.
The Java3D API provides a flexible platform for writing interactive $3 \mathrm{D}$ graphics programs. It shares some similar VRML 3D modeling features, and can also be used to view and interact with VRML worlds. With Java3D API, developers can take advantage of a simple, high-level programming model that enables them to build, render, and control the behavior of $3 \mathrm{D}$ objects and visual environments.

To summarize, Java3D is designed to be a more general 3D environment. With the Java3D APIs, users can directly capture the 3D scene by using the mouse, change viewpoints, zoom in/out, and rotate the $3 \mathrm{D}$ model to observe the model behavior in the best way.

\subsection{Choice of Java3D}

A growing number of engineers in the 3D modeling and design communities are using this technology for cross-platform, 3D graphics application development and deployment. Regarding the application context, the aim is to establish a consistent environment based on Java so that all the components in the system can interact with each other more easily. The Java3D APIs are, therefore, chosen for developing the client side in the new version of Teamproject viewer instead of preliminary VRML plug-in. The FEA model processing is still undertaken by the server, while $3 \mathrm{D}$ rendering and update as well as synchronous update of other windows are all performed by the client (Figure 1).

The advantages of Java3D are portability, efficient programming, and easy code modification, and a wide open community contributes, tests, suggests, and promotes evolution of the Java3D world [24]. Advantages of browsing Java3D models versus VRML ones are that they are faster, have significant improvement in visualization quality, interactivity, better ability for data storing, portability, internet compliant language (compatibility with standard browsers), complete integration with other Java APIs, adapted to multiprocessing (Java3D is internally multithreaded in order to run in multiprocessor systems). However, the two main weak points of Java3D can be underlined: its high temporary memory and processor requirements for the virtual machine running. Moreover, the Java3D files are bigger than VRML files.

\section{Development of FEA and Viewer Modules}

To enhance FEA data sharing and transfer via Internet, the development of a translator between native NASTRAN and Java3D formats is currently under process. The chosen language for implementing this translator is Java because of its stability, 
platform independence, many implemented functionalities, appropriateness to Internet through JSP, and the opportunities of evolution it offers.

\subsection{Architecture Specifications for the New Modules}

As regards to the development of the new modules, the software architecture has been specified as a collection of six modules: the user interface, the FEA module, the pre-processing module, the processing module, the post-processing module, and the database.

Figure 4 presents the architecture specifications for the new modules.

- the user interface: The user interface is developed in order to provide Web-based access to the data files or databases. This interface enables users to dynamically select data they want to visualize, as well as how they wish to visualize them.

- the FEA module: This module may use the NASTRAN or ANSYS solver to carry out analysis.

- the processing module: The processing module simply establishes the relationships between the vaults and the FEA module.

- the pre-processing module: The pre-processing module reads, analyzes and processes the files upload in the system to identify and extract the required data. It also provides a $3 \mathrm{D}$ viewing of these required data.

- the post-processing module: The post-processing module generates a $3 \mathrm{D}$ viewing of the processed model. A dynamic model is generated according to the user's request. This model resulting from NASTRAN or ANSYS translation is a Java3D formatted file.

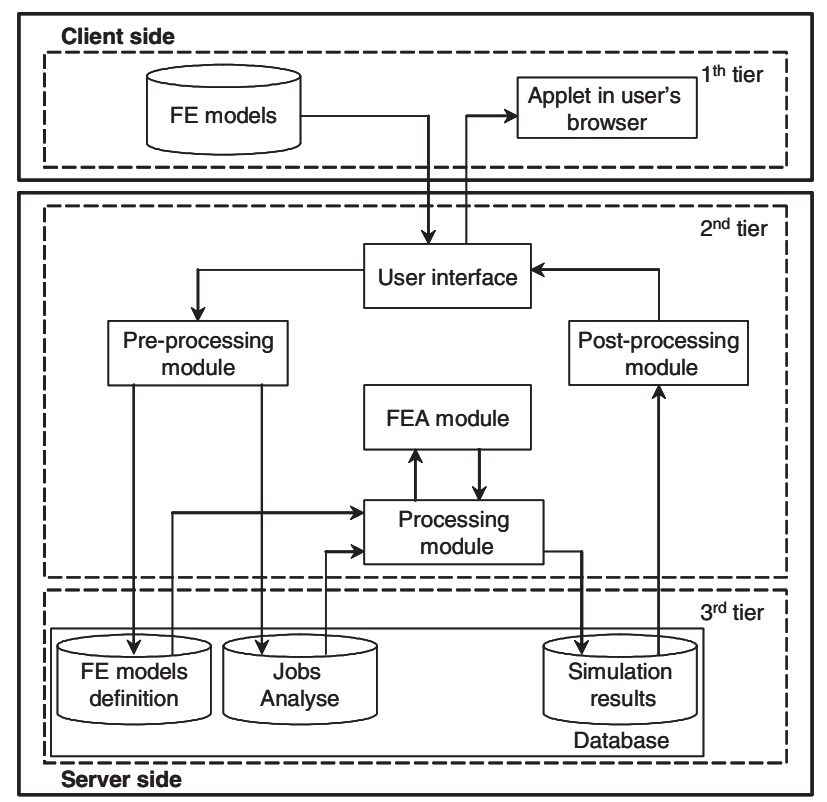

Figure 4. Architecture specifications for FEA and viewer modules.
- the database: The database stores all the data (FEA models, jobs, simulation results) and provides an interface to communicate with the other modules.

\subsection{Results}

Java3D APIs are really suitable for complex 3D modeling structures. Unfortunately, if Java3D APIs provide a rich set of features for creating 3D objects, it also requires too many line of code even to set up simple shapes. However, compared with VRML, which was used in the preliminary version of the Teamproject viewer module, the Java3D compiled code is less cumbersome in memory. But, at the same time, Java3D code is more difficult to program than VRML. Real technical training is absolutely necessary to understand well the concepts and approach of Java3D programming.

Based on the first results, the use of the Java3D APIs to display a complex 3D modeling structure as a Web format seems to be promising. Indeed, the pre-processing files, used by NASTRAN solver, can be translated via Java3D APIs. The translation of these files is relatively fast and easy. With regard to the first promising results, the Java3D APIs seem to be really convenient to carry out a complex 3D modeling structure issued from NASTRAN files. This API could efficiently be used to model the whole of the $3 \mathrm{D}$ structures issued from NASTRAN into a web display format.

\section{Conclusions}

Using Internet as communication support allows the implementation of new methods and tools enabling collaborative engineering in a remote and distributed design project approach. An asynchronous Web CSCW, such as Teamproject, can significantly improve project management and sharing of information between partners. The implementation of such a kind of Web CSCW is easy because it is fully based on Internet and OpenSource features. Teamproject may provide a real added value in the management of design projects. It offers a fast and efficient access to the issues of mechanical design and structural analysis. Without this kind of software, these data require the use of tools with a huge corporate know-how and expertise, especially in FEA field.

This article has introduced the use of Web technologies in mechanical design project. The architecture and the main features of the asynchronous CSCW developed by Ideamech Company have been described. Regarding the users' needs for communication, coordination, and cooperation in collaborative engineering, the following key functionalities of Teamproject can be underlined: projects and documents management, 
message notification, files sharing, CAD and FEA viewing. Based on a survey of available technologies, the choice new 3D data viewer based on Java3D has been made and its specifications have been detailed.

\section{References}

1. Shen, W. (2003). Editorial of Special Issue on Knowledge Sharing in Collaborative Design Environment, Computers in Industry, 52(1): 1-3.

2. Huang, G.-Q. and Mak, K.-L. (1999). Web-based Collaborative Conceptual Design, Journal of Engineering Design, 10(2): 183-194.

3. Zhuang, Y., Chen, L. and Venter, R. (2000). CyberEye: An Internet-enabled Environment to Support Collaborative Design, Concurrent Engineering Research and Applications, 8(3): 213-229.

4. Kvan, T. (2000). Collaborative Design: What Is It, Automation in Construction, 9(4): 409-415.

5. Huang, G.Q. (2002). Web-based Support for Collaborative Product Design Review, Computers in Industry, 48(1): 71-88.

6. Zhang, S., Shen, W. and Gheniwa, H. (2004). A Review of Internet-based Product Information Sharing and Visualization, Computers in Industry, 54(1): 1-15.

7. Xu, X.W. and Liu, D.T. (2003). A Web-enabled PDM System in a Collaborative Design Environment, Robotics and Computer Integrated Manufacturing, 19(4): 315-328.

8. Qin, S.F., Harrison, R., West, A.A., Jordanov, I.N. and Wright, D.K. (2003). A Framework of Web-based Conceptual Design, Computers in Industry, 50(2): 153-164.

9. Burkett, W.C. (2001). Product Data Markup Language: A New Paradigm for Product Data Exchange and Integration, Computer-Aided Design, 33(7): 489-500.

10. Kan, H.Y., Duffy, V.G. and Su, C.J. (2001). An Internet Virtual Reality Collaborative Environment for Effective Product Design, Computers in Industry, 45(2): 197-213.

11. Tay, F.E.H. and Roy, A. (2003). CyberCAD: A Collaborative Approach in 3D-CAD Technology in a Multimedia-supported Environment, Computers in Industry, 52(2): 127-145.

12. Zhang, Y., Zhang, C. and Wang, H.P. (2000). An Internet based STEP Data Exchange Framework for Virtual Entreprises, Computers in Industry, 41(1): 51-63.

13. Rezayat, M. (2000). The Enterprise-Web Portal for the Lifecycle Support, Computer-Aided Design, 32(2): 85-96.

14. Morris, S., Neilson, I., Charlton, C. and Little, J. (2001). Interactivity and Collaboration on the www - is the 'www shell' Sufficient?, Interacting with Computers, 13(6): 717-730.

15. Klaas, O. and Shephard, M.S. (2001). Embedding Reliable Numerical Analysis Capabilities into an Enterprise-Wide Information System, Engineering with Computers, 17(2): 151-161.

16. Sun, Q. and Gramoll, K. (2002). Internet-based Distributed Collaborative Engineering Analysis, Concurrent Engineering Research and Applications, 10(4): 341-348.

17. Bourdakis, V. (1996). From CAD to VR; Building a VRML Model of London's West End, In: Proceedings of 3rd-UK VR-SIG Conference, Leicester, UK, July 3.
18. Ando, H., Kubota, A. and Kiriyama, T. (1998). Study on the Collaborative Design Process over the Internet: A Case Study on VRML 2.0 Specification Design, Design Studies, 19(3): 289-308.

19. Duffy, V.G., Wu, F.F. and Parry, P.W. (2003). Development of an Internet Virtual Layout System for Improving Workplace Safety, Computers in Industry, 50(2): 207-230.

20. Gardner Group (1998). A Distributed Architecture for Design Environment, In: Proceedings of the IEE Colloquium on Web-based Knowledge Server, London, UK, June.

21. Eloranta, E., Hamerib, A.P. and Lahti, M. (2001). Improved Project Management through Improved Document Management, Computers in Industry, 45(3): 231-243.

22. Apte, V., Hansen, T. and Reeser, P. (2003). Performance Comparison of Dynamic Web Platforms, Computer Communications, 26(8): 888-898.

23. Huang, B. and Lin, H. (2002). A Java/CGI Approach to Developing a Geographic Virtual Reality Toolkit on the Internet, Computers \& Geosciences, 28(1): 13-19.

24. Walsh, A.E. and Bourges-Sevevier, M. (2000). Core Web3D, Prentice-Hall PTR, Indianapolis.

\section{Dr. Benoît Eynard}

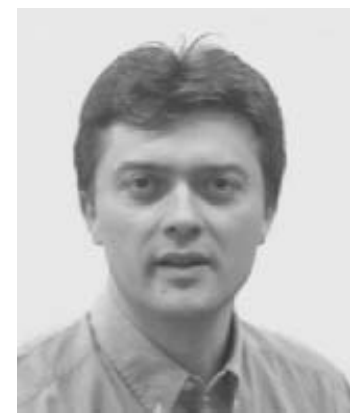

Dr. Benoît Eynard is currently Assistant Professor of Mechanical Engineering in the Department of Mechanical Systems Engineering at the Troyes University of Technology (France). He is also a member of the Laboratory of Mechanical Systems and Concurrent Engineering (LASMIS). He received his $\mathrm{PhD}$ degree from the University of Bordeaux 1 in 1999. His $\mathrm{PhD}$ deals with Engineering Design and Computer Integrated Manufacturing. Currently, his research interests include Concurrent Engineering, Collaborative Design, Product Data Exchange, Product Lifecycle Management, Engineering Knowledge Modeling and Reuse.

\section{Sébastien Liénard}

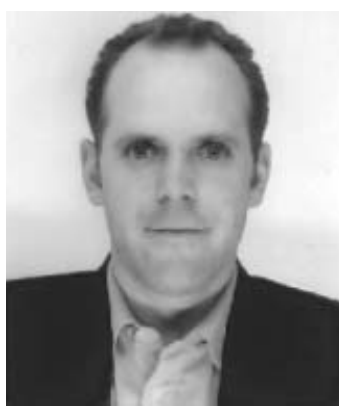

Sébastien Liénard received his Engineering degree in Mechanical Systems from the Troyes University of Technology (France) in 1997. He spent four years in the USA working on a NASA technical center - the Goddard Space Flight Center - as lead analyst for the Inflatable Sunshield 
In Space (ISIS) space flight experiment (a pathfinder for the Next Generation Space Telescope). In the late 2000, Sébastien came back to France to start IDEAMECH (www.ideamech.com), a toulousian consulting company providing mechanical engineering services to aerospace firms: structural analysis, design, etc. Currently, he is working on European Space Agency (ESA) contracts with industrial partners for the development of the next generation of space structures also called the Gossamer Technology, which will enable the use of very large structures required for future space missions.

\section{Sébastien Charles}

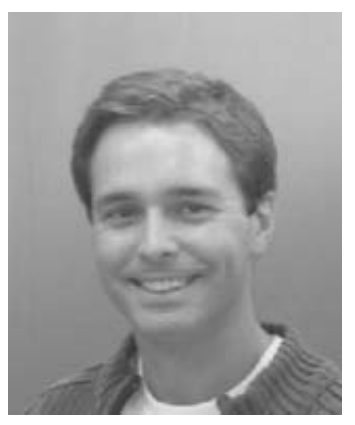

Sébastien Charles is a $\mathrm{PhD}$ student at the Laboratory of Mechanical Systems and Concurrent Engineering (LASMIS) at the Troyes University of Technology (France). He received his Engineering degree in Mechanical Systems from Troyes University of Technology in 2001. His research interests include Concurrent Engineering, Collaborative Product Development, Product Lifecycle Management, Design and Simulation Integration, Management and Exchange of CAD and FEA data, and new STEP standards.

\section{Aurélien Odinot}

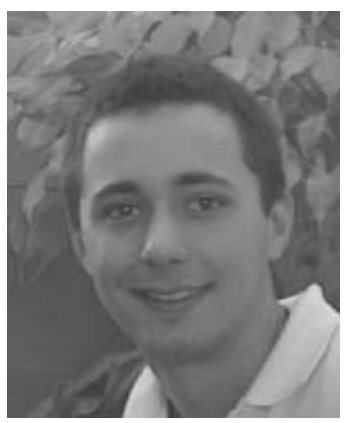

Aurélien Odinot is a $\mathrm{PhD}$ student at the Laboratory of Mechanical Systems and Concurrent Engineering (LASMIS) at the Troyes University of Technology (France). He received his Engineering degree in Mechanical Systems from Troyes University of Technology in 2003. His subject deals with the integration of product lifecycle management within projects of mechanical design. His research takes place in the Technology Resource Centre ESTIA INNOVATION, which is specialized in tools and methods for product design. At ESTIA INNOVATION, he is involved in a regional technology transfer project dedicated to PDM systems for SME companies. 